\title{
Tuff, tailored and tiny: under the skies of surgery
}

\author{
F. M. Riegler
}

Published online: 2 August 2016

(C) Springer-Verlag Wien 2016

Dear reader,

excitement fulfills these very lines, as they are scrolled down by your beautiful, sensitive, orange skin encircled, computer tablet cell phone television screen tested eyes. The eyes and the brain seem to get stuck within the web for many. Principles of oncology frequently claim: Outbalance the benefits. Calculate the side effects. Previously, when long-haired men meticulously searched for the dark side of the moon, one loved to stare into the multi-colored deep and endless oceans of a girl and a boy. Who came into shine after the sun? Did eyes stop to teach a lesson today? Watch out! Physicians know: eyes sing about health, faith and disease, histories and off-stage memories. Those hands are touching. Touching they are, verily. Legacies are imprinted on the stars, stone and our phantasy. May the pair of your eyes continue to stare, mingle, echo and shine.

\section{Exclusions}

Going in line with the echoes of the very ancient times lemon taste melodies tune of all: are you sure not to serve any of the powers and despotisms in the world? Are you sure that you do not serve any of the political, economic and social systems of power, greed, hate and envy, without knowing it? Conceptually it is worth proofing this issue and to question yourself. Here we go.

\section{F. M. Riegler ( $\triangle)$}

RefluxMedical, Mariannengasse 10/9, 1090 Vienna, Austria e-mail: martin.riegler@refluxmedical.com

\section{Day time tune}

Did you ever consider that your eyes are unique, amazing and full of fascination. Ex cerebro they come like universe sensing ears, nose, tongue, mouth, throat, gullet, lips, face, hairs, esophagus, stomach, gut, very gut down to the anus cum ano since annu innu anna and atum. In between porosis cheese thyroids, stretta parotis, retrosternal chest in all thymo hamstery, liver lung breathing gall way all osteo secretions haemo into the pancreas: insula insulina oceans when the pacific fails within the circuit of milky way metabolism. Sugar strokes them all: brain, heart, lungs and the periphery of the planets within the system. These facts matter and are the straightforward realities of circumstances and as such are the papers presented within this issue of European Surgery.

\section{Nocturnal surgeries}

It is worth assuming, that a considerable part of the data presented within the papers published in this issue of European Surgery have been obtained during nighttime surgeries. As nighttime-surgery consumes, it offers a unique opportunity. Lack of sleeping time is outbalanced by the amazing and outstanding chance to step out and watch the early morning skies above. One hours before sunrise one might follow a fascinating cosmic event within the endless screen saver of our universe. Based on the platform circling around its own axis and the sun in concert with other planets and asteroids of our solar system, the early morning skies reveal a deep truth, which has been well taken in all the ancient myths of human mankind. As such you may bath within the mirror of heavens and follow the polars and zodiac signs. While the early morning breeze freshly airs your hair you observe the sun steadily rising against the background 


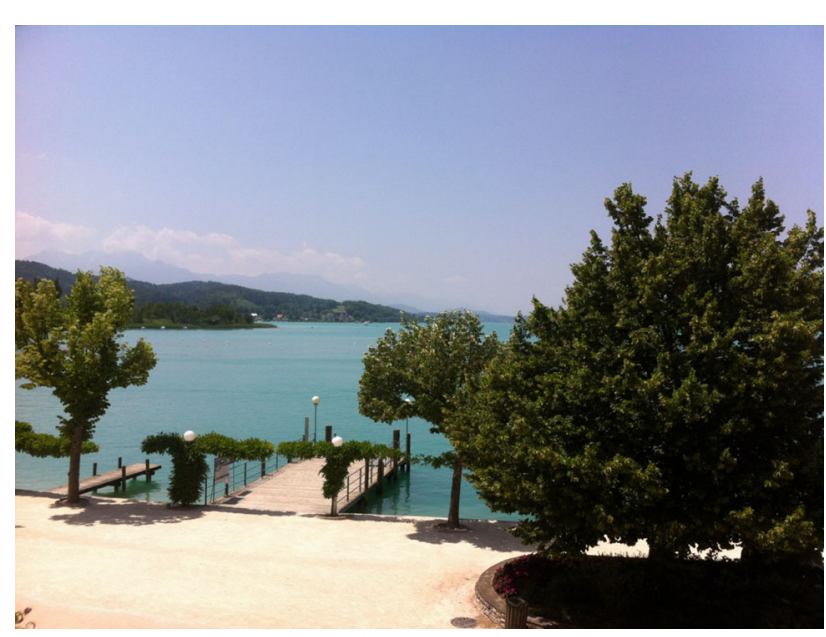

Fig. 1 The image aims to mirror the idea of the author that lakes model heavens' mirror, as outlined in the text. Image obtained in Pörtschach, Wörthersee, Carinthia, Austria, Europe using iPhone technology

of a sign of the zodiacs. Going in line with the ancient legacy of mankind these zodiacs house the sun, are the house of the sun (beth) and once upon a time there rose a concept, where the sun and the stars became the gods and the gods danced around the sun, moon, Milky Way and zodiacs and thus myths have been composed to keep in mind: the world is the mirror of heaven and whatever mankind translated into art, architecture, music, etc., aimed to mirror cosmic events and astronomical knowledge on our planet. Thus the cosmic turntable of the zodiacs became the basis of images well taken within the forceps of Gilgamesh, Torah, Hesiod, Homer, pyramid texts, coffin texts, Popol Vuh, feathered serpents, stars, angles and birds. The myth around Osiris, Isis, Seth and Nephtys represents a major scientific paper dealing with surgery, orthopedics, traumatology and minimal invasive surgery (NOTES of note: transnasal, transrectal approach). May it remember the traces of major medical knowledge and expertise of an ancient lost civilization?

Following the night shift surgery during the early morning hour before sunrise you may take a swim in one of the beautiful central European lakes which then serve as a mirror of the heavens (Fig. 1). And here the surgeon may say: I am going to swim within the mirror of my heaven, as the surface of the lake reflects the events on the cosmic screen saver above your head. And within this scenery you may connect yourself to the ancient myth and wisdom of ancient times. In addition it proofs that the sensitivity and awareness for the heavens' mirror is adequately pre-formatted within your brain, even in the brain of a surgeon. Here it is ridiculous to state the rumor which considers that there exist opinions in the medical arena, who believe, that surgeons lack brain, when compared to the members of other disciplines. Insecurity creates bias, which in turn excludes fruitful op- portunities. A star watching fisherman based in the dawn of the age of Aquarius may tune: as in heaven so on earth; as in the brain, so it turns out to happen in the rest of the body. Taken together, what has been named psychosomatic diseases in the past justifies to be considered and understood as the manifestation of heaven's mirror within the soma of man. Thus, for example, the reflux-affected esophagus turns out to be the question mark world axis of the modern human being to echo the lack of respect, acceptance, tolerance, humility and discipline. Remains to be questioned the consequences of the above suggestions for modern personalized disease-management?

\section{Upbeat}

Trocar mounted minimally invasive harmonic missile scalpels ride with modeling pride through all the wonderful cavities of the human body, painting with multiple colors of innovation and motivation to express treatment without hesitation and point it out in order to save the heart beating live quality promoting sun from going down, off set, and to keep the kidneys swinging, keep the gut floating and bring it to the adequate and correct mediation with the powers of the major great net, web-based and highly influential. Big flood of enteritis. Huge curving down the rims of the sigma diverticula finding themselves in a state of necrotizing inflammation and at the end of the day the cancer takes it all from the belt of zodiacs. The hands of the surgeon heal. No one got the right to cloud the sky and prevent the sun from shining, as the sun, and this is the truth, shines for everyone, and there is enough space on this beautiful planet for everyone. Skies cry rain when it has to happen, when there seems to be too much hate, envy and greed. Going in line with this suggestion and based on the very base line of a reggae music, the rainbow spectrum of papers presented within this issue of European Surgery may also open your mind to assess $(p<0.0001)$ : do not worry about a thing, and everything will be all right, as the citation from the dread lock medical director Jamaica green island watery rivers running with a smile for YOUR EYES reader pointed out to become a so called duppy conqueror.

Life is a train, the rails mirror the insecure destiny of our horizon (i. e. fusion of the old Egyptian concepts of Horus and Orion), man decides the speed and not the direction and, if at will to "change", one may stop that train and step out. May someone else pick it up and speed through the clouds of smiling destinies. Thus, all lives go back to the stars and fulfill the space with sense of humor, laughter and poetry: we are all one and all is one and all flows, floods, files and flies through the mastery of our individual perception as THE TUNE OF MOOD. 


\section{Downbeat}

Here we go for another blues, and the old man offshore climber fisherman on his duty to find the virgin before Aquarius takes over the lead opposite to the lion, he says before closing the black holes in his sky: maybe roots rocking reggae would have been better for the Ben Ben Stone central Europeans. Tears remain and laughter raises the mountains of science towards the understanding of methods driven models, data driven concepts, publisher driven impact factory routine points for the consumers and consumption of the overall ruling medical academical arena: publication counts citation to the equation plus minus by relevance. At the end of the day we have a new total amount of arguments to justify stock market outbalanced low shock treatment all over the globe. Tears of the blue planet cry out loud and lift up to the sky and rain back water likewise into the sea of the emotion of the individual scientist basic academical researcher from Harvard to Bangalore, from Tokyo to USC, from Philadelphia to cream the bread London in status nascendi brexit igitur, from Havanna to Honolulu, from Sydney to fundamentally under-tun- neled Styria. So what, all behaves within a continuous stream of CHANGE and endless search for HARMONY.

\section{Off beat}

Become a follower of the secret of your eyes, foster justice, respect and understanding for a new and better world to come in surgery, medicine, humanity. Otherwise, our good old planet will consider a shake flood to root us back to the soil. So far, it is fine to see an increasing number of women and men to consume soil for treatments of various diseases. Stay tuned and foster your sight.

Acknowledgments The author thanks his patients whose medical histories help to get a feeling for the myth of modern mankind and to openly understand the essence of disease: lack of attention i.e. humility, respect, discipline etc. In addition, the author thanks his friends and colleagues for supporting the fascinating project. Finally, it is justified to keep in mind: we ALL have to thank our parents and families for our existence, support, motivation and acceptance.

Conflict of interest The author(s) declare that they have no competing interests. 